\title{
EN TORNO AL CULTISMO MEDIEVAL: LOS DESCENDIENTES HISPÁNICOS DE DULCIS
}

\author{
EL NúCLEO DEL PROBLema
}

Para cualquier observador acostumbrado al análisis histórico, salta a los ojos la peculiaridad del comunísimo adjetivo español dulce. Comparado, por un lado, con su base latina, DŭLCE (M), y por otro, con ciertos congéneres -ante todo, doce en gallegoportugués, pero también doux douce en francés moderno y dolce en toscano-dulce parece un latinismo neto, a base de tres rasgos distintivos: la $u$ en vez de la $o$, que es el producto normal de la u latina (cǔRRō $>$ corro); la $l$ que de ordinario cae ante la velar asibilada (FALCE $>$ hoz); y la $-e$ en vez de cero, que nos seduce a evocar el ejemplo de Calce $>$ coz (verdad es que NOCTE > esp. ant. noch terminó por convertirse. en noche).

Existe una importante contraprueba de lo anómalo del desarrollo de dulce; y es que en español arcaico y dialectal no faltan precisamente aquellas variantes ( $d u z$, doz, duce, doce, etc.) que se acercan al ideal de la transmisión en línea recta por conducto oral y sin estorbos o desvíos. De ser así, parece imponerse la triple conclusión de que en lo antiguo el léxico español acogía productos normales o casi normales de DuLCE, asemejándose en este respecto al léxico portugués, italiano, etc.; de que los dialectos han conservado algunas huellas de tal uso; y de que el idioma literario igual que la lengua coloquial común han optado en favor de un latinismo - ya antes de finalizar la Edad Media.

Sin embargo, si aceptamos tal interpretación, se plantea otro problema: ¿Cuál es la fuerza que empujó a la gran mayoría de los hablantes, ya hacia 1300 , en la dirección de un latinismo tan acendrado? La primera reacción a tal pregunta será la de alegar el uso frecuente y muy típico del concepto de dulzura y de la propia voz DuLcis en la lengua eclesiástica, ora latina ora vulgar. Argumento irrebatible, pero no enteramente satisfactorio; porque si entra en cuenta la religión, tan católica era España como Portugal, Francia 
e Italia; sin embargo, las lenguas de aquellos países de abolengo y cultura espiritual tan afines no han acogido el cultismo, optando por las formas populares ${ }^{1}$.

En otras palabras, se necesita un factor más que explique, uniéndose al cultismo latente de la ralea de Dulcis, el rumbo que siguió esta voz en castellano y en ningún otro romance. Si no me engaño, es ésta una buena ocasión para acordarse de un brillante hallazgo de Jules Gilliéron que no obtuvo la resonancia de que disfrutaron sus hipótesis sobre las repercusiones de la homonimia.

Examinando los primeros mapas lingüísticos de su atlas, el genial dialectólogo suizo reparó en que ciertas palabras de tipo parisiense (es decir, standard) se infiltraban donde los habitantes de aldeas vecinas no podían ponerse de acuerdo sobre el uso local. En tales disputas, que provocaban excesiva fragmentación regional, el pedir prestada una voz de incontestable autoridad a la lengua prestigiosa de la capital permitía poner fin a toda clase de roces y equívocos. Dicho de otro modo: en ciertas circunstancias el préstamo a la lengua literaria llega a tener un valor terapéutico. Prueba elegante de tal suposición es el hecho de que las palabras en cuestión no cundían paulatinamente, sino que parecían caer del cielo, atravesando zonas muy apegadas al uso dialectal. Se trataba de verdaderas voces paracaidistas, que se abalanzaban sobre territorios lingüísticos afligidos de dudas y desacuerdos.

Aplicando esta idea tan sugestiva al español y extendiendo un poco la definición de la enfermedad y del remedio ${ }^{2}$, se puede sostener que, andando reñidas las preferencias locales por $d u z$, doz, duce, doce, etc., los hablantes se asieron de un cultismo como la solución más aceptable para todo el mundo.

Pero aun estos dos factores no agotan la variedad de causas que hoy entrevemos tras el fenómeno observado. Los adjetivos románicos forman una categoría netamente delimitada, una clase cuyos miembros se apoyan mutuamente en lo formal. Los hay de dos, tres o más sílabas (duro, amargo, cariñoso); los hay que son oxítonos, paroxítonos y proparoxítonos (cortés, noble, misero); pero no hay

1 Verdad es que el francés antiguo toleraba la forma semiculta (mejor dicho, casi culta) dulz (Chanson de Roland), ante todo como epiteto de France (véase Joseph J. Duggan en $R P h, 22$, 1968-1969, p. 46), y que la lengua moderna adoptó la variante de la etapa intermedia, doux, en vez de *deuz, igual que prefirió, tras largo titubeo, loup 'lobo' a leu, bajo la presión de louve 'loba'.

2 Para una primera tentativa de aplicación véase mi articulo (en prensa) "La vacilación fonética como causa de una pérdida léxica: en torno al desarrollo de GAUDËrE y GAUDIUM en hispanorrománico", que ha de salir en el Homenaje a $D$. Fernando Antonio Martinez. Sobre el concepto de "discontinuous expansion" es provechoso leer R. JAkOBson en Style in language, ed. T. A. Sebeok. Cambridge, Mass., 1960, p. 351. 
en la actualidad, ni nunca hubo, que sepamos, en gran número, adjetivos monosílabos en español, lo cual abogó desde luego, en un momento crítico, por la adopción de la variante culta dulce, o por lo menos duce, y contra la generalización de sus contrapartidas populares (doz, duz), que tendían a aislar la palabra en lo rítmicoacentual. Por otra parte, caracterizaba el desarrollo del español medieval una lucha muy reñida entre los nexos intervocálicos -ls-, -ns-, -rs- y su convergente reducción a $s$, con multitud de ultracorrecciones, casos de titubeo y aun extensión a $\zeta$ (fonsado 'ejército' como reflejo de FossĀTU; onso como representante dialectal de uRsu 'oso' y zonzo, sonso 'estúpido' como producto de (īN)sulsu 'soso'; esp. almuerzo frente a port. almoço). En tal clima de inseguridad no es de extrañar que la restitución de la $l$ ante $\zeta$ en dulce, aunque fuese provocada en lo primero por un anhelo cultista, también iba al encuentro de una poderosa tendencia del habla popular. Por último me parece innegable que - $l \zeta$ - como nexo secundario (según se observa en alçar < *ALTIĀRE) apoyó en determinado momento el cultismo dulc(e) en su lucha contra variantes más populares.

\section{ANÁLISIS DE OPINIONES ANTERIORES SOBRE D U L C E}

La conjetura que acabo de desarrollar no coincide, excepto en su primera componente, con las opiniones que los eruditos han formulado hasta ahora. Me parece que vale la pena pasar revista a esta multitud bastante heterogénea de hipótesis (u observaciones sueltas). En una primera etapa se trataba de mera identificación (por lo visto, muy fácil en este caso concreto), sin preocupación por el conducto de la transmisión; corresponden a la segunda etapa varios conatos - por lo demás, mal coordinados-de averiguar tal conducto.

La propia transparencia etimológica de dulce se opuso a que el problema aguzara la curiosidad y sutilizara el análisis de los primeros filólogos, quienes a veces se dejaban distraer por un aspecto secundario o un pintoresco rasgo medio fortuito de la evolución. Así, S. de Covarrubias [H]orozco, después de catalogar dulce como producto de Duzcis, recordó su uso en la poesía (Garcilaso), citó un paralelo (la predilección de Petrarca por dolce) y observó que 'dulce' es el polo opuesto de 'amargo' y, a la vez, de 'agrio' 3 . T. A. Sánchez, mezclando intuiciones felices con átomos de erudición medievalista y con sospechas infundadas, declaró que las lecciones dus y dulce alternaban en los manuscritos de Juan Ruiz y que dulcema y dulzayna se referían al mismo instrumento de música ${ }^{4}$. R. Cabrera

3 Tesoro de la lengua castellana, 2* ed., t. 1, Madrid, 1674, f. 223v.

4 Colección de poesias castelianas anteriores al siglo xu, t. 1, Madrid, 1779, p. $386 ;$ t. 4,1790 , p. 303. 
construyó un puente directo entre esp. dulz-or, -ura y lat. Dulcôre, a pesar del evidené obstáculo en el plano fonético ${ }^{5}$. F. Diez se permitió el lujo de omitir un adjetivo tan diáfano de su diccionario original (1853) y en dos revisiones sucesivas, després de habex señalado, en su gramácica comparada, la ocasional supervivencia de la Ŭ latina en voces españolas como dulce (y culpa, cumbre, curso, duplo, escucho, puño), subrayando el contraste entre esp. dulce y port. doce ${ }^{6}$. P. F. Monlau no prestó ninguna atención a la anomalia fonética, pero divirtió a sus lectores con alusiones a presuntos congéneres celtas y egipcios?. A. de Cihac agrupó la pareja lusohispánica dulce/doce con it. dolce, cat. dols [es decir, dols], ant. fr. dols y rum. dulce, sin ahondar en el problema de las divergencias, que saltan a la vista ${ }^{8}$; su diccionario llegó a ser la principal fuente de información de F. J. Simonet, el fundador de los estudios mozárabes ${ }^{9}$. Cuando, a partir de la tesis de $\mathrm{Ch}$. Joret ${ }^{10}$, se pusieron de moda las investigaciones sobre las sibilantes del antiguo español ${ }^{11}$.

- Diccionario de etimologias de la lengua castellena, ed. J. P. Ayegui, Madrid, 1837, t. 2, p. 253.

- Grammatik der romanischen Sprachen, t. 1, Bonn, 1896, p. 146; y con cambios mínimos, $3^{n}$ ed., t. 1, 1870, p. 167. Diez descubrió el mismo contraste en esp. azufre: port. ensôfre $\mathrm{y}$, en dirección opuesta, honda : funda, plomo : chumbo, sordo: surdo y os(s)o : urso. En cuanto a los resultados divergentes de la $l$ en final de sílaba, Diez postuló una cáda espontánea de la $l$ ante consonante en port. doce y esp. soso (port. ensosso) $<$ (în)sursu, dada la ausencia de variantes añ̌iguas con ou. Distinguió tal desarrollo de tres evo luciones rivales: a) la conservación de la lateral; b) su vocalización; c) su true que ocasional con $n$ o $r$ (Grammatik pp. 244-246; y con cambios notables. s. ed., pp. 206-208).

7 Diccionario etimoligico de la lengua castellana, 2" ed. (preparada por J. Monlau), i881; el pasaje corresponde a la p. $626 a$ del reimpreso, Buevos Aires, 1941 (la edición original de 1856 no está a mi alcance).

8 Dicionnaire d'élymolegie clactromane. Élémenls latins, Frankfurt, 1870, p. 84. El autor pone en el misno nivel esp. dulceza, un próstamo tardío levemente disfrazado, y rum. dalceată; no reconoce el parentesco entre esp. dulzor y rum. dulconre; y se apoya en diccionarios poco fidedignos al rastrear los. equivalentes esparioles del verbo indulcesc.

"Glosario de voces ibéricas y latinas usadas entre los mozarabes.... Madrid, 1888, p. 181 .

$10 \mathrm{Du} C$ [latin] dans les langues romanes, Paris, 1874, B.E.P.... t. 16, p. 140 (dulce agrupado con alcangar, troçir, etc, en el poema del Cid) y p. 147 (queda mencionado, pero sin explicar, el contraste entre dilce y doce).

11 Me limito a unos pocos síntomas de indiferencia: reseña que publicó G. Baist en ZRPh, 6 (1882), 169-170, sobre J. Connu, Étude sur le "Poème du Cif:", recherches élymologiques (silencio absoluto); A. Hosping, Zur Geschichte des lateinichen $G$ vor $E$ und I im Romanischen, Halle, 1883, pp. 58-60, 63, 85, 100 , 106 (comentarios matizados, con haslización exacta, sobre los descendientes francoprovenzales y retorrománicos de bulcas y "ADDUlCaks, frente a una clasificaciún mucho menos sutil de dulce y doce); R. Y. Cuervo, "Disquisiciones sobre ancigua ortograha y pronunciación castellana", RHi 2 (\$895), p. 21 (brevisima 
las vicisitudes de Dulcts hubieran debido atraer la atención de los contrincantes ${ }^{12}$, a unque, a decir verdad, dulce brillaba tanto por su presencia como por su injusta omisión de los estudios de entonces.

Sólo en la última década del siglo pasado el perfil de dulce comenzó a dibujarse con mayor nitidez. Se acumulaban poco a poco los datos filológicos; en el glosario que acompaña la crestomatía medieval de $\mathrm{A}$. Keller figuran la variante anticuada $d u l z$ y el chocante abstracto dulçora, que a primera vista parece cruce de dulçor y dulsura ${ }^{13}$. En el primer tomo (1890), tan influyente, de su gramática comparada W. Meyer-Lübke colocó esp. dulce (habiéndolo seleccionado como ejemplo típico del desarrollo fonético) en el mismo nivel que su homógrafo rumano $y$, lo que hoy resulta aun más grave, que engad. [duč] y sic. [duči] ${ }^{14}$. Al año siguiente, $P$. de Múgica entonó una nueva melodía, proponiendo fr. doux como modelo o fuente inmediata de la antigua variante española $d u s^{15}$.

alusión, que se repite en la versión revisada de esta monografía; véanse las Obras inéditas, Bogotá, 1944, p. 405); J. D. M. Ford, "The Old Spanish sibilants", Studies and Notes in Philology and Literature, Harvard, 7 (1900), 36-39; J. Saroïhandy, "Remarques sur la phonétique du $\xi$ et du $z$ en ancien espagnol", BHi, 4 (1902), p. 200 (alusión a la rivalidad -después de 1550- de las grafías dulçe y dulze). Addolciare, el equivalente toscano de endulzar, pertenece al léxico de Dante (Inferno, VI, 84).

12 El silencio de C. Michä̈lis de Vasconcelos, Studien zur romanischen Wortschöpfung, Leipzig, 1876, $\$ 28$ e índice alfabético (a pesar de su promesa de prestar atención a la alternancia $l e \sim c:$ p. $224 a$ ), se achacará a la falta de cualquier escisión semántica, condición preliminar -según ella- para que se hable de auténticos dobletes ("Scheideformen"). Nótense también el escaso interés de P. Förster, Spanische Sprachlehre, Berlin, 1880, p. 107; el elocuente silencio de observador, en general, tan agudo y alerta como Baist en su primer esbozo de una gramática histórica ("Spanische Sprache", \$§ 23 y 54; forma parte del Grundriss de G. GröвER, t. I, Strassburg, 1888); el discreto desentendimiento del marqués de Valmar en su notable glosario (selectivo) que acompaña la edición académica (1889) de las Cantigas alfonsinas; así como la calculada evasiva de E. GoRra, Lingua e letteratura spagnuola delle origini, Milano, 1898, $\$ 31.33(u, \bar{o})$ y $\S 104$ ( $l$ ante consonante). Por otra parte G. Gröber con pleno derecho pasó por alto la familia de Dulcis en sus "Vulgärlateinische Substrate romanischer Wörter", ALLG, tomos 1-6 (1884-89), dada la falta de bases hipotéticas.

13 Altspanisches Lesebuch mit Grammatik und Glossar, Leipzig, 1890, p. $168 b$.

14 Grammatik der romanischen Sprachen, t. 1, Lautlehre, Leipzig, 1890, $\$ 477$ (la $l$ agrupada); cf. la formulación enigmática del $\$ 483$ ("port. doce aber span. dulce"). Sobre el problema aparte del abstracto rumano dulcoare ver t. 2, Formenlehre, 1894, $\S 465$.

15 Gramática del castellano antiguo, Berlín, 1891, $\$ 43$, bajo la rúbrica "Palabras francesas". Por otro lado, Múgica pasó por alto dulce en los \$\$ 81-82, donde discutió buitre, trucha, etc. (¡declarando semicultismos a cuño y uña!), y en los $\$ \S 195-196$ (donde opuso alto, caldo, gulpeja y halcón, que todos conservan la $l$, a escuchar y cuchillo, que la pierden). 
Las tres ediciones del diccionario etimológico comparado de G. Körting muestran, como era de esperar, un conocimiento defectuoso del inventario de las formas hispánicas $y$, además, pecan por cierta timidez en la jerarquización de tales formas; aun así, prestan cierta ayuda del lado bibliográfico ${ }^{16}$.

El advenimiento del siglo xx marcó un ritmo muy acelerado de la discusión; de aquí adelante los hispanistas, animados por la ayuda indirecta que les prestaban los romanistas de otra especialización ${ }^{17}$, no sólo proclamaban su opinión con toda claridad, sino que a veces no titubeaban en anunciar sus cambios de orientación. Así G. Baist, largo tiempo $(1882,1888)$ indiferente a las peripecias de dulce, distinguió en 1906 una veta indígena (dulce) -que no calificó ni de popular ni de culta- de ciertas antiguas infiltraciones de galicismos (duce, duc, -aina) ${ }^{18}$. En su primera monografía sobre las sibilantes, $\mathrm{O}$. J. Tallgren [-Tuulio] segregó dulce como cultismo neto, equiparando la pareja medieval $d u c ̧ e / d u z$ a coçe/coz y hoce/hoz (las seis formas convivian en el diccionario de rima -entonces inédito- de Pero Guillén de Segovia, de hacia 1430); para explicar duçe, Tallgren - prisionero de los neogramáticos-

16 Lateinisch-romanisches Wörterbuch, Paderborn, 1891 (29 ed., 1901 y $3^{3}$ ed., 1907), con un cambio en la numeración de las bases. (La familia de DuLcis no figura en los agregados de A. Scheler al diccionario de Diez.) En 1901 Körting añadió al inventario dulzaina y acentuó el contraste entre DuLc. OR $\mathrm{e}$ *-1OR (rum. dulcoare frente a fr. douceur, etc.). En ninguna de las ediciones explicó la divergencia entre dulce y doce; comentó el contraste entre dulz-or y doç-ura; reparó en el carácter indígena de it. dolcezza, rum. dulceaţăa, a diferencia del status adventicio y de la corta trayectoria de esp. dutceza; no reconoció como préstamos it. dolzaina y esp. dulzaina; tampoco analizó con acierto la distribución de los prefijos AD- e IN- en los derivados verbales. Quedan como residuo aprovechable de los esfuerzos bien intencionados de Körting la alusión al fr. ant. adouchier 'Linderung erfahren' (según A. Tobler), verbo paralelo a asoagier, la fuente de assuage en inglés; la colección de formas retorrománicas: dolts, dults, duts, etc., que el lexicógrafo pidió prestada a la excelente Raetoromanische Grammatik de T. GARTNER; así como sus referen. cias a sendos estudios de G. Cohn y S. Puscariu.

17 Llama la atención el papel desempeñ̉ado por los dacólogos, tan entusiastas en esta materia. O. Densusianu (en su "magnum opus": Histoire de la langue roumaine, t. 1, Les origines, París, 1901, p. 169), identificó el bajo lat. in-dulcire (-āre) como punto de partida para el verbo incoativo indulcesc (mac.-rum. ndultsesku) 'endulzar', etc. S. PuşCARIU, Etymologisches Wörterbuch der rumänischen Sprache, Heidelberg, 1905, § 833, aprovechó este informe, ampliando, ya por cuenta suya, el ámbito de puLcōre ( $\$ 555$ ), de donde extrajo it. ant. dolcore, y colocando al lado de dulceaţă tres congéneres: it. dolcezza, gen. ant. doźeça y engad. dutšetssa.

18 Ver la. $2^{\text {q }}$ ed. (1904-06) del t. I del Grundriss, $\$ \S 50$ y 54: parece que una fugaz alusión a esp. ant. $d u z<\mathrm{p} \overline{\mathrm{u}} \mathrm{x}$ en el $\S 24$ se debe a una interpretación errónea de un importante pasaje de Juan Ruiz. 
estaba dispuesto a operar con la forma intermedia *douce ${ }^{19}$. Pero, pasados dos años, ya estaba inseguro de si su explicación era superior a la de Baist ${ }^{20}$. Al redactar la primera versión de su dicciona. rio etimológico, hacia 1910, Meyer-Lübke metió esp. dulce entre corchetes, separándolo así de dálm. dolk, logud. dulke, friul. dolts y de todos los otros reflejos romances -ya mencionados- del adjetivo latino ${ }^{21}$; al revisar su diccionario, transcurridas dos décadas, reafirmó su opinión, dando todavía mayor relieve al aislamien. to de dulce por un procedimiento sencillo: agrupó esp. ant. $d u z$ con cat. dolৎ y port. doce 22 . J. D. M. Ford, superando su apatía de

19 "Las $z$ y $\&$ del antiguo castellano iniciales de sílaba", Mémoires de la Soc. néo-philol. à Helsingfors, 4 (1905.1906), p. 25. El autor registra (a)coçear $y$, en ese contexto, coloca calçar en el nivel de dulçe.

20 Estudio sobre la "Gaya" de [Pero Guillén de] Segovia, Helsinki, 1907, p. 79. Recurrió a la grafía-medio fonética- *dówçe para fijar la supuesta forma intermedia; llamó la atención sobre la chocante alternancia dulçear duçeado, frente a dulçe, de cuyo enlace con la categoría de cultismos ya no estaba absolutamente convencido.

21 Romanisches etymologisches Wörterbuch (REW), Heidelberg, 1911-1920, 2799. He aquí las innovaciones: port, aducir como término metalúrgico (tal vez una errata; los diccionarios traen adoçar); un compuesto galorrománico (Doubs) ; dos itinerarios reconstruidos por primera vez (fr. ant. doussaine $>$ it. ant. dolzaina, esp. ant. dulzaina); eliminación de una gratuita base hipotética (Dulcima, lanzado por Körting) y de una superflua asociación con una voz piamontesa, por la cual había abogado $C$. Nigra. Gozan de autonomía DULC $\bar{A}_{R E}$ 'endulzar' (\$2791), verbo representado en dialectos italianos, por ejemplo tosc. (r)addolcare, y el abstracto bulcon (\$ 2793); supeditado a éste a fin de cuentas, el it. ant, dolciore figura como proyección de prov. ant. dolsor, mientras esp. dulzor disfruta de cierta independencia.

22 Más allá de la corrección de errores elementales, la revisión del $R E W$, efectuada entre 1930 y 1935 (dependiendo de la entrega), presentó un cuadro más adecuado del desarrollo. Meyer-Lübke introdujo la base INDULCäre 'endulzar' ( $\$ 4384 a$ ), apoyándose en it. indolcare 'ablandar', campid. (es decir, sardo meridional) indulkai 'tostar el cáñamo'; alegó pruebas del cambio semántico 'dulce' $>$ 'querido' (Francia, Italia); y señaló varias especiali. zaciones de significado, por ejemplo en el Delfinato, donde el descendiente de Dulce designa el 'hígado', mientras en los dialectos del sureste adu equivale a 'lugar expuesto al sol' (ya en la primera redacción del diccionario había figurado redu 'tiempo de primavera'). De todo ello puede sacar el hispanista una lección importante: mientras en Francia y en Italia (incluyendo a Cerdeña) se produjo una proliferación morfológica y semántica, España fue testigo de un extraordinario aumento de variantes fonéticas del propio adjetivo. Para un estudio detenido del idearium de Meyer-Lübke en los años treinta conviene tener presente también ciertos pasajes de su monografía "Die Schick. sale des lateinischen $L$ im Romanischen", Sitzungsberichte Leipzig, 86 (1934), ante todo las pp. 64 (vegl. dolk), 67 (surs. $d u \dot{c}$, pero la variante más arcaica $d u l \grave{c}$ sobrevive en Domleschg), grödn. douć frente a Abtei duce (se trata de

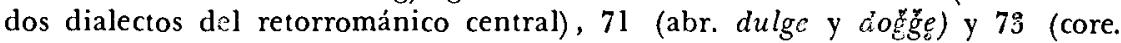
dorce). En lo esencial, estos datos corresponden a los materiales explayados en el $R E W$, pero aquí figuran en otra perspectiva. Desgraciadamente, para el español, el autor se apoya demasiado en el flojo artículo de Brüch (1930), 
principiante, se apresuró a declarar̃ dulce un cultismo ${ }^{23} \mathrm{R}$. Menéndez Pidal, quien, en 1904, había descuidado por completo a dulce, sus varianes y satélites y, todavía en 1908, prestaba atención prin. cipalmente a problemas secundarios de sus peripecias semánticas ${ }^{24}$, se acordó, al revisar su Manual, de la extraña convivencia de duce, en los textos medievales, de $d u z$, en dialectos modernos y antiguos, y de duice, entretejiendo así los hilillos de una transmisión compleja -escrita y oral ${ }^{25}$. A. Zauner pasó por varias etapas; en su

cf. infra nota 29; además, se ocupa con cierto detenimiento en dos trabajos anteriores, el de I. Bacinkschi (cuyas conclusiones rechaza para el iberorromá. nico) y el de F. Schürr (que tampoco le deja muy convencido), los cuales salieron, respectivamente, en $\operatorname{los}$ tomos 44 y 47 de la $2 R P h$. Forma el eje del artículo entero el análisis pormenorizado del carácter velar, dental o palatal de la $L$ lazina en determinadias posiciones. Aplazo para otra ocasión el examen de ese trabajo y de las sustanciales críticas que provocó (reseñas de G. Rohlss, E. Richter y E. Gamillscheg).

23 Oid Spanish readings [¿a ed.], Boston, 1911 (y varias reimpresiones), "Etymological vocabulary" (ausente de la $1^{\text {" }}$ ed.), p. $215 a$. Por otra parte, el eshozo de gramática histórica que encierra la "Introducción" guarda silencio respecio a $d u(l) c e$ en los pasajes relevantes (pp. xviii, xxxix).

24 En su monumental edición del Cantar de Mio Cid, Madrid, 1908-1911, pp. 632-633, Menéndez Pidal se limitó a una polémica con T. A. Sánchez y A. Bello en cuanto al sentido preciso del sintagma espacia dulce. Pero el bosquejo de gramática histórica que ocupa parte del primer tomo separa expresamente dulçe de los cultismos incontrovertibles craz y mundo, clasificándolo en carnbio con azufre, buitre, cumbre y explicando así la anomalía de la $u$ : "La $l$ agrupada influye también en dulge". No hay la menor alusión a dulçe ni en el estudio anterior sobre el Poema de Yúcuf (1902), ni en la monografía -posterior al Manual elemental de gramólica $(1904,1905)$ - sobre el dialecto leonés (1906), la cual sí presta atención, aunque sólo de pasada, a los reflejos locales de CALCE y FALCE.

25 Así, las ediciones cuarta (1918) y quinsa $(1925,1929)$ del Manual lla. man "regular" a la sibilante de $d u l_{\xi} e$, colocando la voz en el nivel de torçer y vençer; en cuanto a la $l$, "se pierde" (1918), "se pierde absorbida en una $u$ precedente" (1925). Reanudando la discusión con motivo de la última revi. sión de su libro (6* ed., 1941), el autor ya se expresa con mayor cauiela, aludiendo a la "vocalización vacilante de $l$ ", pero se abstiene de aplicar ninguna etiqueta clasificatoria a duice. En el $\$ 63.2 a$ vuelve a examinar el problema, partiendo de los nexos de consonantes tolezados en final de silaba, entre los que descuella $l z$, a juzgar precisamente por dulz. Además, sin que el indice alfabético lo revele, el autor menciona "dulz o duz" a propósito de la apócope de la vocal en español antiguo (\$78.2). En sus Origenes del español (1926. 1929. 1950) Menéndez PIDal registra (\$9) la grafía dulce que encontró en una de las Glosas emilianenses, pero ni siquiera en la $3^{n}$ ecición, muy ampliada. se detiene en el testimonio del mozírabe (dol-ce, ge), que por otra parte llamó la atención a un mero alicionado en materia lingüística como J. $\mathbf{B}$. TREND, The language and history of Sprin, London, 1953, pp. 35-36. Mayor interés para el especialista encierman las observaciones sobre moz. e hisp.-ár. (yerba) dols/dolche que hace, a la zaga da su maestro M. Asin Palacios, $R$. LAFEs en las pp. $189-190$ de su nutrido artículo "La apócope de la vocal en castellaro antiguo; intento de explicación histórica”, en Estudios dedicados a 
guía para los estudiantes de la lingüística romance hizo caso omiso de dulce/doce ${ }^{26}$; a los pocos años, redactando su gramática elemental de español antiguo, se adhirió a la arriesgada conjetura de Tallgren ("duz DULCE über *douz wie foz aus *fouz FALCE"), pero sin insinuar la paradoja a que daba lugar la coexistencia de dulce, contentándose con traer -a la zaga de Menéndez Pidal-cruz y mundo como únicos ejemplos del desarrollo (semi) culto de la $\breve{\text { Ŭ }}{ }^{2 \tau}$.

Entre las dos guerras continuó el diálogo, sin que el lector de hoy note ningún vigoroso rejuvenecimiento de método ni tampoco ningún nuevo empuje dado a la documentación. Se vislumbran huellas de cierta "atomización" de la pesquisa, contra la cual hubo de rebelarse más tarde, con impresionante éxito, el estructuralismo. Así el propio Zauner, en los años veinte ${ }^{28}$, observó cierto paralelismo entre los resultados de -LS- y -LT- (PULSĀRE > puxar, MULTU $>$ mucho), y esta idea encantó tanto a J. Brüch que interpretó de modo igual -uLć- $>-u c$-, alegando en particular la biografía de DulCE $^{29}$; aunque desterrado al Nuevo Mundo, L. Spitzer, a su vez,

Menéndez Pidal, t. 2, Madrid, 1951, pp. 185-226. Lapesa se refiere de pasada también a $d u l z$ en Berceo (p. 215) así como a calz (p. 216); pero quizás sea más notable el material que acarrea sobre Arganz, entonz y esto(n)z, Florenz, Lorenz, Ponz, romanz, Sanz (pp. 185, 186, 193, 207, 208, 209, 215, 222) ; asi como sobre Alfons(o) $\sim$ Amfós $\sim$ Anfús y Orens (pp. 203-204, 217).

26 Véase Romanische Sprachwissenschaft, Leipzig, 1900, pp. 57 y 98; $2^{a}$ ed., t. 1,1905 , pp. $51,61,63,105 ; 3^{\text {a }}$ ed., t. 1,1914 , pp. $48,59-60,99-100$.

27 Altspanisches Elementarbuch, Heidelberg, 1908, $\$ 11 f(a$ ante $l), \S 12 e, g$ (las fuentes de $u$ ), $\$ 51$ (las fuentes de $l$ ). Estos pasajes adolecen de varios descuidos: debilita la explicación que ofrecen de puso 'colocó' lo que se ha sacado en limpio sobre coser $<\overline{c o}(n) s(u)$ ere; el eslabón entre dudo y dubitó fue dubdo (port. duvido), de ninguna manera *dobdo (¿confusión con cobdo 'codo' < cuBrtu?) ; con motivo de cruz no habia que rechazar rotundamente la conjetura de Cornu, la cual armoniza bien con el "Zeitgeist" del cristianismo primitivo (CRUX sigue a LũX; aunque en toscano conviven luce y croce, en francés el triunfo de la forma popular croix coincide con el triunfo de LŪMEN [lum-ière], en merma de LÜx); esp. ant. topo significaba 'ratón' o 'topo', pero no 'rata'; calcea produjo, en lo antiguo, calça, no [*]calza.

28 Véase la $2^{\mathrm{a}}$ ed. (1921) del Elementarbuch, $\$ \S 16$ y 58 , asi como la nota -en traducción de R. Lapesa- "Esp. pujar y soso", RFE, 5 (1929), 154 160 (conclusión: "Por de pronto nada se opone seriamente a un paso meramente fonético de PULsĀRE a pujar"). Se echa de menos una separación neta de (em)puxar, con una $x / \check{s} /$ común a los dialectos hispánicos $y$, al parecer, antiquísima, y mucho, con una $c h / \check{c} /$ limitada al castellano y relativamente tardía.

29 "L'évolution de l'l devant les consonnes en espagnol", RFE, 17 (1930) 1-17. He aquí los dos pasajes-clave: "L' $i$ atone de -uis-, -uit- devint fricative ... palatalisa l's suivant, le $t$ suivant et s'assimila, après, à ces consonnes $\dot{s}, \dot{t}$, absorbées par elles; -uis-, -uit-passèrent à -us-, -ut- et de même -uits- [dans * duitse provenant de DULCEM] à -uts-; plus tard, la $s$ s'est changée en $\dot{s}$ dans toute la Péninsule ibérique" (p. 9) ; “ $i$ atone de - $u$ - devient consonne palatale et palatalise la consonne suivante [mucho, puxa, duce] excepté $m^{\prime \prime}$ (p. 17). 
se dejó seducir por el raciocinio de sus compatriotas ${ }^{30}$. Pero en general los eruditos, enmarañándose cada vez más en detalles, se encontraban en un callejón sin salida. Cuando se releen hoy sus trabajos de entonces, saltan a la vista ciertos sintomas de cansancio y decaimiento. Así, en su juventud, V. García de Diego, aunque no operaba con más de dos productos divergentes del adjetivo latino (duz y dulce), los colocó hábilmente en unos contextos bien matizados ${ }^{31}$, prestando especial atención a $\operatorname{culcrT}(\mathrm{R}) \mathrm{A}$ 'colchón, al. mohada' -voz que, su peculiaridad acentual aparte ${ }^{32}$, se asemejaba a dulce en el encadenamiento de los fonemas. Desgraciadamente, al reanudar sus pesquisas al cabo de algunos decenios, García de Diego ofreció una reconstrucción mucho menos certera ${ }^{33}$.

Al lado de la corriente principal se notan ciertas manifestacio-

Nótese lo desdibujado que sale aquí el cuadro cronológico. La respuesta de ZAUNER: "Encore une fois $l$ devant consonne", RFE, 17 (1930), 286-290. ya desatiende el caso de dulce. Para un análisis muy distinto de $(e n) \operatorname{sos}(s) o$ (y una crítica del artículo poco feliz de A. Alonso sobre çonço), ver un estudio mío que salió en $R L i R, 24$ (1960), 201-253, especialmente 221-225.

30 "Spanish bosar 'to vomit'...", Lan, 15 (1939), 50-51. Partiendo de vulsus 'espasmódico' y convulsiō 'convulsión', Spitzer equiparaba las tres trayectorias vulsus $\rightarrow$ bosar, însulsu $>(e n) \operatorname{sos}(s)$ o y DULCE $>d u z$.

31 Elementos de gramática histórica castellana, Burgos, 1914, p. 41: "Ante $s$ se combina en $j$, PULSĀRE pujar; ante continua $c$, $f$ vacila: precedida de $a$ se vocaliza en $u$ en FALCE $h o z$, pero se conserva en *EXCALFARE escalfar [aplicado principalmente a los huevos]; precedida de $o, u$, vacila en culcitra ant. colcedra, cocedra, DULCE dulce, duz, pero se pierde en sUlPHURE azufre, CULMEN cumne, cumbre frente a uLMu olmo..." Precede a este pasaje -que tal vez adolezca de una excesiva confianza en condiciones fonéticas y de una escasez de alusiones a estratos léxicos- una ristra de regionalismos interesantes.

32 La forma básica era culcita; pero la variante "subterránea" en -TRA está bien atestiguada, aflorando en Petronio y en las glosas (para los detalles remito al diccionario etimológico de Ernout y Meillet). La variante hubiera sido de escasa importancia de no haber producido un cambio de acento (siguiendo la pauta familiar de CATHEDRA e INTECRU), lo cual nos anima a distinguir con todo rigor el tipo cúlcita (conservado en esp. colcha) del tipo rival culcítra que presuponen el dálmata meridional (Ragusa) colchitra y el español medieval co(l)cedra. Ojalá Meyer-Lübke hubiera hecho tal distingo con mayor nitidez. Sobre este sector del léxico ver el artículo -sustancial, pero de lectura difícil- de P. Aebischer, "La literie et l'histoire du matelas d'après des matériaux médiévaux romans", $Z R P h, 55$ (1950), 303-337.

33 Gramática histórica española, Madrid, 1951, pp. 52 (“dulz, salz, calz ... arz ... entonz, alcanz") y 54 ("Tras ć ha vacilado la lengua entre la pérdida y la vocal de apoyo, hace y haz de FASCE, pez y pece, coz y coce, duz y duce 'dulce', formas con -e en Nebrija y en el extremeño y salmantino". El Diccionario etimológico español e hispánico, Madrid, 1954, contiene datos útiles en ambas partes; véanse las pp. 23b, 30a, 144b, 237b (dulce al lado de $d u z$ ) en la primera y el $\$ 2370$ en la segunda. Este último rebosa de variantes poco conocidas: salm. $d u(l) z$, jud.-esp. dolce (también dolzor), ribag. dolso (con ultracaracterización de la desinencia), etc., pero adolece, en cambio, de cierta falta de aseo, organización y claridad de contornos. 
nes aisladas, inconexas de curiosidad, en varios niveles de seriedad y probidad científicas. En R. J. Cuervo, tras un periodo de indiferencia (véase la primera edición de sus Anotaciones..., Bogotá, 1867-72), no tardó en despertarse un vivo interés por dulce a medida que iba revisando y ampliando su libro ${ }^{34}$. Por otra parte, la literatura de los últimos sesenta años no carece de recapitulaciones, a veces poco penetrantes, de dictámenes anteriores ${ }^{\mathbf{3 5}}$ ni tampoco de observaciones vagas $o$ inexactas ${ }^{36}$. Algunas conjeturas independientes son tan flojas que apenas si merecen una refutación explicita; asi hay demasiadas incógnitas en la tentativa de E. H. Tuttle de explicar dulce como cruce de [*] dolce y duce, suponiendo a) la descendencia de éste de pulce a través de *doice y b) la efímera existencia de aquél ${ }^{37}$. A veces los eruditos han logrado so-

34 Así, ya la 4 a ed., Chartres, 1883, p. 521, nota 22, proyecta mucha luz. sobre duz/duce. Cuervo registra col. (Bogotá) cañaduzal 'cañaveral' frente a fil. cañaldulzal (extraído del vocabulario de Blumentritt; por cuenta mía, remito a esp. ant. cadadia $\sim$ cadaldia) y a gall. cañaduz; trae esp. ant. duz y mej. ant, duce (Valbuena, Grandeza mejicana, c. vi) y cita el distingo que hacen los bogas (domiciliados en la cuenca del Río Magdalena): "Duce es el duce, y dulce es el dulce nombre de Jesú". Téngase presente, para la semántica y la sintaxis del adjetivo, el sustancial artículo que trae el Diccionario de construcción y régimen, t. 2, p. 1338a-134la.

$35 \mathrm{He}$ aquí unas pocas migajas, que aduzco principalmente a título de curiosidad. J. Alemany Bolufer, Estudio elemental de gramática histórica..., $3^{\mathrm{a}}$ ed., Madrid, 1911, $\S 95$, agrupa dulce (única variante que cita) no sólo con alba, alio, palma, sino, lo que parece menos venial, con pulga, que tiene un nexo secundario. A F. HANSSEN, Spanische Grammatik auf historischer Grundlage, Halle, 1910, $\$ 15.2$, llaman la atención los dobletes dulce/duz sólo en el marco de la apócope y de la subsiguiente reacción a ella. Pasados tres años y asimiladas las críticas que provocó la versión alemana de su libro, menciona en su Gramática histórica de la lengua castellana, en la sección de los sufijos, los cuatro derivados dulcedumbre y dulz-azo, -or, -arrón, pero no se anima a interpretar inequívocamente la transmisión del radical. P. Fouchí, "Études de philologie hispanique", $R H i, 76$ (1929), p. 150, reprocha a Menéndez Pidal el no haber justificado el contraste entre gulpeja, pulga, sulco (surtido, a decir verdad, bastante extraño) y esp. ant. duz $<$ DULcE pero sin darse la molestia de ofrecer un remedio. G. B. Pellegrini, Grammatica storica spagnuola, Bari, 1950, alude a la alternancia de dul\% y dulçe en textos medievales ( $\$ 44.2$ ), luego agrupa a duçe, duz con azufre y -en lo que concierne a la caída de $l$ (pero no a las peripecias de $u$ )-con el fitónimo ova < ulva, terminando con la observación lacónica: "In dulce (mod.) ì stata ripristinata la $l$ per influsso colto" (\$ 72).

36 Asi, W J. EnTwisti.e, The Spanish language together with Portuguese, Catalan, and Basque, New York, 1938, p. 264, quizás hubiera debido reservar para amer. duce el marbete "occidentalismo" en lugar de "arcaísmo".

37 Hasta cierto punto el pasaje en cuestión, que se encuentra en sus "Notes on the Spanish palatals", MPh, 8 (1910-1911), p. 596, anticipa la futura controversia (1929-1930) entre Zauner y Brüch, pero desdibuja grotescamente la realidad, transcendiendo los límites de lo probable: "The development of dulce shows everi more plainly that $\zeta$ was once t.s. Spanish dulce is apparently 
lucionar por lo menos un problema scundario; así, demostrado con viejos métodos filológicos el incontrovertible carácter de italianismo de dulceza, esta voz ya no podía figurar en la reconstrucción de la prehistoria ${ }^{38}$.

En medio de tanto titubeo y de tantas operaciones ejecutadas a tientas ( $y$ algunas veces aun a ciegas), se observa sin embargo un progreso claro, en línea recta: a medida que avanzamos a lo largo del eje cronológico, aumenta el número de textos o vocablos aislados transcritos en alfabeto fonético, ora se trate del equipo de Hamburgo ${ }^{39}$, ora del de Madrid ${ }^{40}$. Así tenemos la seguridad de que en determinados lugares de la Península individuos bien caracterizados en cuanto a su abolengo, sexo, edad, educación, ocupación, hábitos, etc. han pronunciado formas locales de dulce con seseo o ceceo, con pérdida o conservación de la $l$ (o su transformación en $r$ ante consonante, rasgo más bien caracierístico de dialectos italianos ${ }^{11}$ ), con la vocal tónica posterior alta $(u)$ o baja $(o)$, con reducción o caída de la $-\varepsilon$ : [du $\left.\theta_{2}\right]$, [du $\left.\theta_{1}\right]$, [du $\theta$, [do $\theta$ i], [do $\theta$,

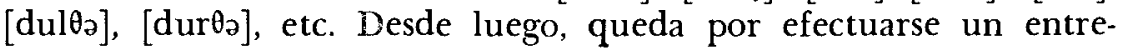

a combination of duce and ${ }^{*}$ dolce $=$ Catalan dols. Old duce and duz, derived from *doice, owe their $u$ to the lost $i$, like mucho = Galician moito $<$ multu. The $o$ of "doice is seen in Galician doce and Portuguese doce. The latter form does not stand for *douce, for Galician does not confuse ou with oi, nor reduce ou to $o$, as Portuguese does". Véase además la nota de TutTle "Hispanic alteru and ALtu" en MLR, 7 (1912), 377.378, en que *doice, ioce < DULCE frente a surco < sulcu y el fitónimo urce < uLICE figuran como ejemplos de soluciones rivales. (Recurriendo a la hipótesis de la vocalización de $l$ ante consonante, para justificar formas inexistentes como *doice y *douce, Tuttle y otros eruditos de su generación muestran -sin darse cuenta de ello- hasta qué punto los hispanistas de antaño dependian todavía de los estudios de francés antiguo, tan bien desarrollados en Alemania). Sobre $u z \sim$ urce se puede acudir ahora al diccionario de Corominas, s.v. dulce.

$38 \mathrm{~J}$. Terlingen, Los italianismos en español..., Amsterdam, 1943, pp. 38,359 .

39 F. KRÜGER, Studien zur Lautgeschichte westspanischer Mundarten, Hamburg, 1914, § 419, señala que el habla provinciana de Zamora ha conservado la $l$ con mayor fidelidad que ei extremeño, pero no se pronuncia ni por ni contra ninguna de las hipótesis con que ha tropezado. Registra [doeę], con una vocal final articulada algo más enérgicamente en el articulo "Mezcla de dialectos", \$26, que contribuyó al Homenaje a Menéndez Pidal, Madrid, 1925, t. 2 , p. 138

40 A. M. Espinosa h., Arcaismos dialectales: la conservación de " $s$ " $y$ " $z$ " sonoras en Criceres y Salamonca, Madrid, 1935 (RFE, anejo 19, p. 9). A próposito de esp. ant. duçe y $d u z$ el autor se limita a invocar un "resultado popular".

41 Así, en antiguo siciliano Surtana correspondia a Sultana; véase la contribución de Francesco Eranciforti a los Studi di filologia romanza offerti a Silvio Pellegrini, Padova, 1971, pp. 21-58. Sobre el uso de Córcega, cf. supra, nota 22. 
tejimiento elaborado de los materiales que siguen rindiendo los textos medievales y de los recogidos y archivados por los dialectólogos.

Habiéndose acumulado, un poco al azar, tantos datos sueltos de carácter filológico y dialectológico, y habiéndose ventilado gran número de hipótesis, en parte contradictorias, era de esperar que la atrevida síntesis etimológica de J. Corominas, efectuada hacia mediados del siglo, marcara un decisivo paso adelante. Por desgracia, el artículo sobre dulce que trae el t. 2, 1955, del Diccionario criticoetimológico, pp. 207a-208a, está muy lejos de haber resultado satisfactorio, aun si se agrega el análisis complementario de cumbre. Huelga decir que no faltan en la abundante colección de materiales que, acarreó el autor unos cuantos datos muy útiles, por ejemplo, ant. arag. dolc -que recuerda el reflejo catalán-, la notable variante dolce - tan afín a la italiana- del ms. $\mathrm{O}$ del Alexandre, esp. clás. aduzar (¿último vestigio, desde luego indirecto, de $d u z$ en la lengua literaria?) y sanabr. doz que, si hacemos caso omiso de la apócope, se acerca al modelo gallegoportugués. También impresiona favorablemente la destilación de unos pocos hallazgos anteriores. Sin embargo, saltan a la vista varias lagunas sorprendentes ${ }^{42} \mathrm{y}, 10$ que es más grave, causa desilusión el análisis de la transmisión.

Descontando implícitamente la posibilidad de causas múltiples (concurrentes) y rebelándose contra la autoridad de Meyer-Lübke, Corominas insiste en que la vocal tónica $u$ en lugar de $o$, que separa esp. dulce de sus congéneres y equivalentes semánticos, no es prueba de cultismo. Las formas primitivas $d u z$ y duce, al modo de ver del autor, deben su $u$ a una cerrazón causada por una semivocal, [i] o [u], que debió de brotar en una de las primeras etapas, y por consiguiente se asemeja a la $u$ de azufre, buitre, cuitre, cumbre, mucho, surco, etc. Todo ello no es inverosímil; pero el autor va más lejos, declarando: "La $l$ de dulce se restituyó no por latinismo, sino por una reacción de los altos estratos idiomáticos, la misma que impuso alto, palpar, calza, etc. (en lugar de oto, popar, coz") 43. $^{43}$. Corominas establece una ecuación entre cultismo y latinismo, oponiendo ambos conceptos en tono polémico al habla de la "Ober.

4: La información de Corominas parece fragmentaria, inadecuada (o inexistente) del lado hispano-oriental: mozárabe y judeo-español. El autor presta escasa atención al aspecto gallego-portugués del problema; se deshace apresuradamente del pasar revista a dictámenes y análisis anteriores (en particular, pasa ligeramente por encima de varios alegatos de un galicismo medieval); no toma en cuenta como criterio etimológico la configuración de la familia léxica.

43 La ecuación de calsa, basado en CALCEA [kalkja], y coc, que continúa CALCE [kalḱe], no representa en este contexto el mejor modo de sugerir la alternancia alomórfica de cals- y coş, por la sencilla razón de que [kj] y [ḱ] constituyen dos puntos de partida distintos. 
schicht", como si ella estuviera exenta de tendencias latinizantes, lo cual ya raya en lo arbitrario. Al negarse a clasificar dulce como cultismo, el autor observa: "No es creíble en palabra de tal naturaleza". ¿Alude al ámbito semántico o al círculo de las personas que la emplean? Refiriéndose de pasada (en la nota 3) a la transmisión de culpa, confiesa sus dudas: "Aquí no es seguro en vista del uso religioso, que hace comprensible un cultismo" ${ }^{44}$. Pero, como siempre ha constado a los historiadores de cultura (máxime a los eruditos literarios) y como ha confirmado de lleno un ensayo de $\mathrm{S}$. Heinimann ${ }^{45}$, dulce, en su infinidad de usos afectivos y metafóricos, se enlazaba muy íntimamente con la tradición poética y religiosa del Occidente. De resultas, el argumento central de toda la demostración de Corominas se derrumba sin remedio ${ }^{46}$.

44 Nada prueba mejor el peligroso grado de atomización de la lingüística románica que la falta de cualquier monografía de conjunto sobre los cultismos. Sobre el ocasional enlace de dos categorías de voces adventicias, véase mi artículo "Préstamos y cultismos", $R L i R, 21$ (1957), 1-61.

45 "Dulcis. Ein Beitrag zur lateinisch-romanischen Stilgeschichte des Mittelalters", $H D A, 2,215-232$. Aun en la latinidad de la región vasca DuLcis, a la par de clemens y PIA, calificaba a la Virgen; véase D. Gifford, "An early white paternoster in Basque?", BHS, 41 (1964), p. 209.

46 Se echa de ver la poca consistencia de Corominas en esta encrucijada tan importante consultando su comentario paralelo sobre cumbre < culminE: "Aunque culmen tenía $u$ breve, es imposible admitir que sea forma culta o semiculta. Como el caso coincide con el de bulcıs $>$ dulce (antes $d u z$ ), sulcus $>$ surco (antes sulco), y con -uch- (-uit-) como resultado general de -ǓLT- -vocablos que por razones semánticas tampoco pueden considerarse cultismos- se impone suponer que en todos ellos la $l$ actuó como fonema cerrante; probablemente la $l$ se vocalizaría primero en $u$ o en $i$, que después de cerrar la vocal precedente seria absorbida por ella; dulce resultaría de una reacción latinizante o más culta, y en surco esta misma reacción (nacida de los diplomas latinos, donde surco se empleaba en el sentido de 'lindero') seria causa de que la $l$ se cambiara en $r$ por la resistencia del vulgo a pronunciar un sonido que en esta posición había quedado fuera de un sistema fonético [¿fonológico?]".- No se comprende por qué una boga "latinizante o culta" logró cambiar $d u z$ en dulce, pero por razones semánticas no pudo coadyuvar previamente a conservar la $\breve{u}$ de $d u z$. También se echa de menos, a propósito de sulco/surco, una alusión al fenómeno -estudiado pormenorizadamente en un artículo magistral de A. Alonso y R. Lida- de que en final de sílaba la $l$ y la $r$ forman un archifonema en varios dialectos peninsulares, llegando a neutralizarse su contraste. En el t. 2, p. 208a, de su diccionario, Corominas se pregunta si port. sulco sería voz culta, olvidado de su categórica observación anterior de que la clase semántica de dicha voz excluye tal suposición. La impresión general es que el docto lexicólogo catalán se ha abalanzado sobre unos pintorescos problemas individuales sin aclarar por adelantado, para sí mismo y para sus lectores, los conceptos básicos con que iba a operar. Tampoco satisface por completo la información que ofrece Corominas en su Breve diccionario etimológico, Madrid, 1961, p. 217a. Por un lado, encanta su virtuosismo, ya que llega a mencionar, a costa de una compresión muy hábil, unas cuantas formaciones bastante raras, como dulzainero, dulzón, edul. 
Resumiendo nuestras impresiones y sumando los reparos que hemos puesto a casi un siglo de investigación efectuada ora al azar, ora metódicamente, podemos sentar lo siguiente.

A los varios rasgos en que los antiguos dialectos centrales de la Península se oponían simultáneamente a los del Oeste y los del Este -situación examinada magistralmence por Mentíndez Pidal en sus Origenes del español (1926, 1929, 1950)-conviene agregar la distribución de $u$ y $o$ (como representantes rivales de la $\breve{u}$ latina) ante determinados nexos de consonantes. Así se explica esp. azufre frente a port. enxofre; esp. gusto frente a port. gosto ${ }^{47}$; esp. mundo frente a cat. mon; esp. dulce frente a port doce y a cat. dolc. En algunos casos debían de correr parejas y apoyarse la tendencia hacia el cultismo y la preferencia más "honda" por la $u$; de ahí mundo y duz/dulce, tan extraños para quien se encara con el español viniendo del francés y del italiano. Parece enteramente superflua la reconstrucción de formas intermedias con los diptongos oi y ou ${ }^{48}$

Sobre este fondo se dibujan con mayor claridad varios desarro-

corar y dulcamara $\sim$ dulce-amara; por otro, causa desilusión su poco esmero en lo que atañe a la cronología; así, dulzura, por cierto, no aparece en 1490 , sino que era un abstracto ya muy caracteristico de la lengua medieval, figurando, por ejemplo, en Barlán e Josaphá, ed. G. Moldenhauer, f. $103 \mathrm{v}$, en Confision del amante, ed. H. Knust, ff. $56 \mathrm{r}, 81 \mathrm{r}, 296 \mathrm{v}, 364 \mathrm{v}$, y en el $M a r d e$ Historia de Fernán Pérez de Guzmán (ed. J. Domínguez Bordona), p. 191, al lado de dulçor (Grail fragments, ed. K. Pietsch, f. 277v; Barlán e Josaphá, ff. 133r, 140v) y de dulcedumbre (Barlán e Josapha, f. 97v). En La Celestina conviven dulce (ed. J. Cejador y Frauca, IX, 42; X, 62) y dulsor (XIV, 133; XIX, 193). Tampoco identifica Corominas el núcleo del problema genérico; se busca en vano una alusión a la supervivencia de duz, duce en ciertos dialectos; y falta un puente que lleve al lector a los compuestos que todavía conservan $-d u z$ como uno de sus elementos. En suma, el artículo salió inferior en varios respectos al que ofrece García de Diego en su diccionario, en general más atrasado. En su edición crítica tan controvertida del Libro de buen amor (1967), Corominas sigue la lección del manuscrito en la estr. 39a: dolçor, rechazando la enmienda de F. Hanssen (dulçor). A propósito de $117 d$ y $118 d$, insiste (quizás con razón) en que $d u z$ significa 'dulce' y no 'guía', polemizando con María Rosa Lida. Su polémica hubiera resultado de mejor tono de haber concedido que $-d u z$ en alcaduz (Fuero de Alba de Tormes, $\$ 138$ ), alcanduz (= núm. 42 en el glosario que preparó R. Oroz de la Biblia medieval romanceada) corresponde, de hecho, a acue-ducto, de modo que duz estaba a caballo de dos familias léxicas.

47 La distribución en dirección opuesta es sumamente rara. No hacen al caso parejas como esp. costar : port. custar (que atañen a los representantes de la $\overline{0}$ ), o esp. oso : port. urso, ya que en este caso parece tratarse de un latinismo puro (¿introducido a lo nejor para evitar el roce con osso 'hueso'?); pero dan que pensar esp. corto y hondo frente a port. curto y fundo

$48 \mathrm{Ni}$ siquiera descario la lejana posibilidad de que en la adopción de interrumpo, ir (frente al pors. interrompo, er) haya desempeñado cierto papel auxiliar la marcada preferencia del español por $u$ ante nexo de consonantes. 
llos ulteriores. Sobre reforzar la predilección popular por la $u$, la corriente cultista tendía a restablecer el nexo -lc-, reducido a una existencia precaria ${ }^{49}$; la reacción a la apócope permitió a los hablantes restaurar (o, por lo menos, generalizar) la variante integramente culta dulce, tomando como punto de partida el antiguo duce ${ }^{50}$. De adoptarse tal enfoque, el influjo ultrapirenaico resulta más débil de lo que tradicionalmente se había supuesto; a lo mejor prorrumpe sólo en la infiltración de dulzor como variante poética de dulzura, aserto que se puede hacer a base del contenido de la cultura trovadoresca y también teniendo en cuenta el testimonio de unas formas arcaicas que se escalonan entre los dos idiomas galorrománicos y el español, por ejemplo dulçora (¿malograda tentativa de conservar el género femenino de douceur?) ${ }^{51}$

\section{ANÁLISIS DE OPINIONES ANTERIORES SOBRE D OCE}

Presumiendo que hasta cierto punto es lícito separar la discusión de gall.-port. doce de la de su equivalente castellano ${ }^{52}$, parece que en este coloquio aparte de los lusófilos se han formulado -en general, con brevedad lacónica- varias opiniones que merecen se las cierna $y$, por añadidura, prometen arrojar luz sobre esp. ant. $d u z / d u l c e$ y otras voces afines. En efecto, los pronunciamientos eruditos sobre los problemas locales que plantea doce forman decididamente una minoría ${ }^{53}$, lo cual nos autoriza a hacer hincapié en

43 La mejor prueba de su escasa resistencia a presiones y tentaciones es el cambio de acalçar y percalçar, de muy transparente derivación y de excepcional sugestividad metafórica, en alcançar (con trueque de nexos y disfraz arábigo) y percance (que ni siquiera luce tales ventajas).

50 Sería esta una de las numerosas consecuencias secundarias de la restauración (a veces falsa) de la vocal final; por esta reacción me explico también el chocante cambio de agua firvient en agua hirviendo.

51 De ordinario, los abstractos españoles en -or guardaban el género mascu. lino heredado del latin; pero en portugués y en español dialectal, igual que en francés.y en provenzal, dejó huellas la tendencia hacia el trueque de género (así a cor, a dor corresponden a el color, el dolor; dentro del léxico español, al lado de el calor la lengua poética admite todavia hoy la calor); de manera que esta división indigena iba al encuentro de la moda provenzalizante. Dudo de que la preferencia de ciertos autores por dulzor ( $y$ análogamente, aunque en menor grado, por amargor), en merma de dulzura ( $y$ amargura) se deba exclusivamente a la disimilación de vocales - de ser asi, ¿cómo se justificaría grosor:- conforme senté en un artículo juvenil redactado en 1939, aunque publicado con un atraso de casi siete años; véase "Probleme des spanischen Adjektivabstraktums", NMt, 46 (1945), 171-191; 47 (1946), 13-45.

52 Véanse, supra, notas 11, 14, 16, 37 y los pasajes correspondientes del texto.

53 Así, A. dos R. GoNçálvez Viana, Apostilas aos dicionarios portugueses. Lisboa, 1906 , t. 1, pp. 319 y $368-369$, registra port. sept. doceiro 'confitero' y docaria 'confitería' ('voces acuñadas por niños?, me pregunto en vez de confeit. 
los de mayor envergadura, cuya solución contribuirá a matizar las hipótesis ya insinuadas.

Las gramáticas históricas de sesgo tradicional -excepto las que dan un vistazo demasiado rápido como para detenerse en tales de. talles ${ }^{54}$ - colocan la transformación de DuLcis en doce en una perspectiva ora ancha, ora estrecha. Puesto que esta vez (a diferencia de lo observado con motivo de los sondeos de los hispanistas) el comportamiento de la $u$ causa menor sorpresa que la caída de la $l$, doce figura de ordinario en el capítulo sobre las consonantes. Entre los iniciadores cabe mencionar a C. von Reinhardstoettner, quien prestó atención a la discrepancia entre: a) DULCE $>$ doce e İNSUL-

eiro, aria, consagrados por la lengua literaria; además, extrae "docissimas [en vez de dulcissimas, tan artificial en portugués como lo son acérrimo e integérrimo en español] laranjas" del reportaje de un viajero (1900) publicado en la revista $O$ Século y dedicado al interior de Paraíba y Pernambuco. Si Dulce dejó huellas en el onomástico español (testigos doña Dulce, nombre de la hermanastra de Fernando III, y la Dulcinea de Cervantes, nombre doblemente sugestivo, ya que evoca el radical de dulce y la desinencia de Florinea), triunfó aún más como nombre de pila en portugués, suplantando la forma indigena Doce; asi, la pastora Dulcina y -cosa que hubiera sido de menor agrado a los lectores de lengua española- el pastor Dulcineo son los protagonistas de la novela bucólica Fortuna d'amor (1573) de A. Lofrasso. No es de extrañar que una forma antroponimica castellana terminase por imponerse en Portugal; el caso clásico de este fenómeno es Diego (cuyo diptongo -ie- es prueba contundente de su esencial castellanismo), que invade el territorio de Diago < DīDĀcu en Portugal y provoca, a título de reacción (o de evasión), la extrañísima forma Diogo, que el propio J. Leite de Vasconcelos, en 1928. declaró inexplicable. De todos modos, J. J. Nunes, Digressões lexicológicas, Lisboa, 1928, p. 37, equiparó los dobletes Dulce/Doce a otras varias parejas: Cipriano $\sim$ Cibrão, Juliano $\sim$ Juião/Gião, Pelágio/Paio, etc., señalando la habitual victoria de la variante culta sobre su rival popular. LEITE DE VAsCoN. Celos, en su ya aludida Antroponimia portuguesa, Lisboa, 1928, p. 29, docu. mentó varios brocies notables: Dulcis como "cognomen" clásico frente al bajo lat. Dulcirius y a la variante lusolatina Dulcidius (monasterio de Lorvão, año ${ }^{850}$ ) como matriz de Doce, Dulce. Véanse además el examen de Dulcidius (nombre de un obispo del siglo iv) y de Dulcevida en Meyer-Lübke, "Romanische Namenstudien, II: Weitere Beitrïge zur Kenntnis der altportugiesischen Namen", en las actas de la Academia de Viena (Silz.ber., t. 184, número 4, 1917, pp. 44 y 58), y las abundantes pistas bibliográficas en la nota de $R$. LApesa, "Aldonza-Dulce-Dulcınea", BBMP, 23 (1947), 48.53, reimpresa en la colectánea $D e$ la Edad Media a nuestros dias (1967), pp. 212. 218, cf. el resumen crítico de E. S. Morby en $R P h, 24$ (1970.71), p. 159. Aunque Aldonza es de descendencia gótica (Aldecundia), la íntima asociación de - $n \varsigma^{-}$y $\cdot l_{\zeta}$ - y el peculiar papel del segmento al- abogan por un estudio de conjunto sobre Aldonga/Dulce y el scudoarabismo alcançar/encalçar; nótese, ade. más, cat. donsayna 'dulzaina' que trae J. Gulsoy, $R P h, 15$ (1961-1962), p. 287.

5it Asi, C. Tagliavivi, Enciclopedia italiana, t. 28, pp. 49-51, resume y caracteriza de esta manera lo esencial del problema: "Importante, ma non difusa a tutti i casi, la vocalizzazione di l dinanzi a consonanti" (menciona tan sólo dos líneas evolucionarias -según él, las principales). 
SU > ensosso (con monoptongo) y b) CALCE $>$ couce, FALCE $>$ fou$c e$, PALPĀre > poupar, etc. (con diptongo); la anomalía estribaba en la falta de una variante con *ou-, como en la tríade souto/soto al lado de salto ${ }^{55}$. La paradoja consiste en que, a lo largo de la época subsiguiente, precisamente los análisis más autorizados del nexo $l+$ consonante proyectan escasa luz sobre las peripecias de Dulce en portugués y en los dialectos contiguos. Leite de Vasconcelos pasó por alto este caso particular en su prestigiosa monografía sobre el mirandés (subdialecto que forma parte del leonés occidental ${ }^{56}$ ), mientras una nota póstuma de $C$. Michaëlis de Vasconcelos ( $\nmid 1925)$ se ciñó a una alusión a la dificultad del caso, que así quedaba por resolver ${ }^{57}$.

Los dictámenes de los especialistas que enfocaron las vicisitudes

55 Grammatik der portugiesischen Sprache auf Grundlage des Lateinischen und der romanischen Sprachvergleichurg, Strassburg-London, 1878, pp. 57-58. Con cierta vaguedad el autor aisla también la pareja BALBU $>$ bobo y SCALPRU > escopro. Hoy consta que bobo es un castellanismo (así MEverLüвке, $R E W^{3}, \$ 898$, siguiendo la pauta de Leite de Vasconcelos); escopro podría representar igualmente un disfraz de esp. escoplo, psro en esta trayectoria léxica se produjo una complicación, ya que se ha identificado la variante (claramente indigena, a juzgar por el diptongo) escoupro, documentada en gallego y en antiguo portugués; $c$. Nunes, Crestomatia arcaica, $2^{2}$ ed., Lisboa y Rio de Janeiro, 1921, pp. lx×xiv-lxxxv, pasaje del que, por desgracia, queda excluido doce.

56 Estudos de filologia mirandesa, t. 1, Lisboa, 1900, p. 286. El autor distingue con toda nitidez tres esquemas: a) conservación de $l$ (primaria: alto, o secundaria: algo); b) su cambio en semivocal (föuce, öutro, múito); c) su transformación ocasional en $r$ (urze, frente a öurzeira). Por lo visto, ni la forma literaria doce, ni siquiera una aproximación local a tál forma, cuadraría con ninguno de los tres esquemas. El silencio de Leire es tanco más impresionante cuanto que en aquel momento las divergencias entre el español y el portugués le tenian muy alerta.

57 "Inéditos, II: História da consoante $l$ em português", $R L u, 28$ (1930) 22-23. En esta nota, tan breve como jugosa, la autora distinguió a) la conservación de la $l$, ora primaria (alto, calva, golpelha, malva, olmo, selva), ora secundaria (delgado, folgar, galgo, salgueiro), de su vocalización en una capa de "vocábulos antigos e populares", con el subsiguiente cambio de [au] en [ou]: outeiro, outro, poupar, souto, toupeira; buitre, cuitelo, escuita, muito, y con la posibilidad de dos fases ulteriores: sea monoptongación: escôpro (cf. orelha, Odiana en posición protónica), también abutre, cutelo, escuto, sea alternancia oi $\sim$ ou : coice $\sim$ couce, foice $\sim$ fouce. Terminó por elegir como las palabras más refractarias a una explicación genética enxôfre 'azufre' ("não sei porquê') y precisamente doce: "Lm cast[elhano] o $l$ perdeu-se, arc. duce, vulg. duz. Em doce de bulce tal vez haja outro caso. Mas indo mais longe ainda, a língua reduziu o ditongo a $i$ a $\hat{o} i$ e $\hat{t} i$ a $\hat{o}$; cf. enxoffe de suzruR". Esa dictamen parese doblemente notable en vista del silencio de la aû́ora en su glosario del Cancioneiro da Ajuda, redactado hacia 1905 y publicado con gran atraso ( $R L u, 23,1920-1922)$; pero de haber salido la nota en vida de la autora, no cabe duda de que ella la hubiera podado y retocado. 
de DulcE en un marco más estrecho se dividen en tres categorías o familias:

a) Algunos investigadores sostuvieron que la $l$ sencillamente cayó en aquella posición. Tal preferencia se deduce, por ejemplo, del modo en que registró el cambio A. Garcia Ribeiro de Vascon. celos ${ }^{58}$. Gonçálvez Viana reconoció el parecido entre las trayectorias de doce y cocêdra < CulçITrA, voz que - según nos constatambién figuraba en los buceos de los hispanistas, pero dio un traspié al rastrear el desarrollo de éste ${ }^{59}$. Leite de Vasconcelos reconoció el paralelismo entre doce $<$ DULCE y ant. port. (h)úçara $<{ }^{*} \mathrm{UL}$ CERA (derivado regresivo de ULCERĀRE) ${ }^{60}$. E. B. Williams llegó a postular una ley fonética aparte para doce y ensosso, sin dejarse influenciar por ciertas tendencias opuestas que están bien documentadas ${ }^{61}$.

b) Otros eruditos persistían en creer en *doice como fase intermedia, a pesar de la elocuente ausencia de tal fase, ora se escudriñen los textos medievales, ora se recojan muestras modernas del habla rural. J. J. Nunes nunca cesó de depositar su confianza en tal concatenación de sucesos ${ }^{52}$; J. Huber, a pesar de su entusiasmo

58 Gramática histórica da lingua portuguesa, Paris y Lisboa [1900], pp. 46. 57: DU (L) CE $\rightarrow$ doce, en compañia de bôca, côv-edo (-ado) 'codo', gósto, môsca, ôdre, pôdre, etc.

59 Apostilas, t. 1, 315-316. Confiando en Körting excesivamente, aunque casi a regañadientes el autor se dejó seducir a operar - sin la menor necesidadcon el diminutivo culcitula. Hoy se reconoce en colcha una adaptación de fr. ant. colche, derivado de colchier < COLlocāre (véase Corominas, DCEC, t. I, 850a, quien se mueve en la órbita de A. Castro; en lo moderno se ha acuñado couchette). La relációñ entre port. cocêdra y esp. col(c)edra tiene un notable parecido con doce : $d u(l) c c$. Paso por alto aquellas peculiaridades de cocêdra (acentuación fluctuante, alternancia de $\varsigma$ y $z$ ) que no hacen al caso.

60 Lições de filologia portuguesa, $2^{a}$ ed., Lisboa, 1926, p. 294; $3^{a}$ ed., Rio de Janeiro, 1959, p. 269. El comentario de S. da Silva Neto, quien -en esta última edición- aspiró a poner al día el libro, tampoco ahonda en el análisis de doce.

61 From Latin to Portuguese, Philadelphia, 1938, $\$ 38.1 \mathrm{I}$, frente a lo expuesto en el $\$$ 38.1.B. La $2^{\text {a }}$ ed. (1962, I968) ha dejado sin retoques la formulación original.

62 Compéndio de gramática histórica portuguesa, Lisboa, 1919, pp. 77-78, 86. Asiéndose de dobletes como (a)bu(i)tre 'buitre', ba(i)xo 'bajo', ca(i)xa 'caja', chu(i)va 'lluvia', co(i)xa 'muslo', fa(i)xa 'faja', fro(i)xo 'flojo', fru(i)to 'fruto', gra(i)xa 'grasa', ro(i)xo 'morado' (más bien que 'rojo'), Nunes se dejó arrastrar por cierto entusiasmo por reconstrucciones fantasistas, postulando *doice al lado de "cuime 'cumbre' y de *poitro 'potro'. Precisamente el material gallego que aduce en nota (doce frente a coitelo 'cuchillo' < cul 'Teciu y a entroido 'carnaval' < INTrorTu) hubiera debido convencerle de la poca o nula solvencia de doice. Consúltese sobre la extensión dialectal de fruito M. de PAiva BolÉo, Dialectologia e história da lingua; isoglossas portuguesas, Lisboa, 1950 (sobretiro de $B F$ ). 
tibio ${ }^{*}$, fortaleció la hipótesis apelando al testimonio de gall. ant. moge < MULceT 'ordeña', mientras A. Nascentes ofreció su apoyo con tanto desaliño que en el fondo debilitó la conjetura en vez de robustecerla ${ }^{64}$.

c) En dos ocasiones J. Cornu reconstruyó * douce (colocando a su lado, con lógica irreprochable, *insousso) como el eslabón entre DULCE antiguo y doce moderno ${ }^{65}$. Verdad es que en lo actual el gallego muestra una notable cerrazón de la vocal, lo cual, hacia fines del siglo pasado, estimuló a varios autores regionales a favorecer grafías realistas (o descriptivas) como dóce (J. Pla y Zubiri) y doozura (A. Montenegro Saavedra ${ }^{66}$ ). Pesados por separado, tales datos aislados no llegan a autenticar *douce; lo que merece tanta mayor atención cuanto menos fidedigna resulta la variante (presumiblemente espuria) Douce de Aldonça, Dulce, Doce ${ }^{07}$, que hace medio siglo se atribuía a la hagiografía medieval.

Fracasadas las tentativas de dar cierta verisimilitud a ${ }^{*}$ doice y *douce, volvemos con mayor confianza a la ecuación sencilla doce < Dulce, que coincide bien con el desarrollo paralelo del español $d u z /$ duce $<$ DULCE.

63 Altportugiesisches Elementarbuch, Heidelberg, 1933, \$\$ 149.1.1, 222, 248; a lo mejor la alusión a esp. ant. doce en el último pasaje representa mero desliz. Aquí está el núcleo de la hipótesis: "Auffällig bleiben Dulce $<$ doce... und MuLGeT < altgal. moge. Vielleicht ist das $i$ aus $\mathrm{L}$ bei dem Wandel DULCE $>$ "doitse $>{ }^{*}$ dotse $>$ doce und MuLGeT $>$ *moidze $>$ mod. $z e>$ modze $>$ moge in dem $t s, d z$ aufgegangen...; wohl nicht erbwörtlich gestaltet".

64 Diccionário etimologico da lingua portuguesa, Rio de Janeiro, 1932. p. 254a; con una referencia inexacta al precitado libro de Nunes y un resumen excesivamente simplificado del dictamen de C. Michaëlis. Nascentes agrega al inventario el derivado transparente doçal 'variedad de uva negra' (C. de Figueiredo) y declara dulçor un castellanismo ¿a pesar de la preferen. cia del español por dulzura?

65 "Die portugiesische Sprache", $\$ \$ 28$ y 143, en el ya mencionado Grun-

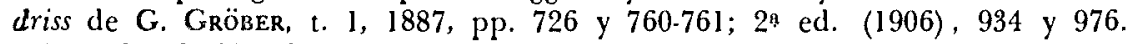
Nótese la alusión del autor a port. ant. exufre frente a gall. xófre y port. enxofre, para no decir nada de esp. azufre; sobre la rivalidad de $e(n)$ - y $a$ - ante ch $\mathrm{y} f / z$ he reunido materiales, observaciones ajenas y alguna que otra idea original en mi artículo "Conflicting prosodic inferences from Ascoli's and Darmesteter's laws?", RPh, 28 (1974-1975), 483-520.

66 Elementos de gramútica histórica gallega, Burgos, 1909, p. 47, quien cita la revista Galicia Moderna, t. 2, pp. 18 y 22.

67 Véase Nunes, "Os nomes de baptismo: sua origem e significação", $R L$, 31 (1933), 38-39, s.v. Aldegundes, nota 4. Me refiero a Alduença/Aldonça (y a otros nombres de procedencia gótica) asi como a port. ant. vergonşa $\sim$ vergonha (= esp. ant. vergüença $\sim$ vergüeña) < VERECUNDIA en mi artículo "Derivational transparency...", $R P h, 25$ (1971-1972), 1-52; consúltense las pp. 25.26 y 31 
En resumidas cuentas, es lícito afirmar que la historia de Dulcis en castellano antiguo abarca dos fases: en la primera (que aquel idioma comparte con el portugués, con gran número de dialectos hispanorrománicos y aun con varias lenguas congéneres) predominaba la fragmentación; en la segunda, privativamente español,, prevalecía la unificación.

Fue la extraña coincidencia de algunas corrientes evolucionarias de carácter "borroso" la que mejor explica la génesis de una ve1dadera superabundancia de variantes -algunas de tipo netamente regional, otras tal vez de índole social o estilística. Sea como fuere, el inventario que los eruditos han recogido a lo largo de un siglo de investigación luce variantes -aun si se hace caso omiso de meras reconstrucciones (por lo demás, poco plausibles): *douce, *douz, *doice, etc. - como dulce y dolce; dolče y dolğe; duce y doce; duz y doz; dulz y dolz; durce; dolso ${ }^{68}$, que también se reflejan en derivados: esp. ant. aduçar frente al mod. endulzar, etc. ${ }^{69}$ Entre las aludidas corrientes fonéticas que se perfilan mal, a pesar de muchas tentativas de reconstrucción por parte de eruditos beneméritos, conviene destacar la apócope; el desarrollo de la $\breve{u}$ latina ante un nexo de consonantes; y la desaparición de la $l$ en final de sílaba. Parece que todos estos factores de desarrollo espontáneo actuaron juntos, y que a ellos se agregaron, como fuerzas independientes, el cultismo y la moda provenzalizante, aunque estas dos fuerzas parecen haber intervenido en dosis limitada.

Presidió a la segunda fase otra alianza de factores, corroborando la hipótesis general de "solidaridad de fuerzas" o de "causación múltiple" 70 en lingüística diacrónica. Para que triunfase dulce sobre sus numerosos rivales y para que tal proceso quedase carae-

68 Para no complicar el cuadro, paso por alto variantes meramente gráfi-

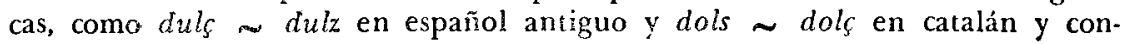
sidero como espuria la grafía dus que abunda en ediciones anticuadas de textos medievales. Tampoco tomo en cuenta la proliferación tardía a que dio empuje la escisión del idioma en dialectos ceceantes y seseantes; así, la transcripción fonética confirma que el judeo-español emplea (a)dulsar 'offrir de la confiture', dulse 'doux', 'confiture, conserve', para recurrir a las notas exactas que tomó C. M. Cresws, Recherches sur le judéo-espagnol dans les pays balkaniques, Paris, 1935, p. 2963.

69 Remito al lector, para los detalles, al diccionario monumental de Coro. minas, enteramente satisfactorio para este propósito.

70 Si no me engaño, "solidaridad" es un término que, hacia medio siglo, introdujeron, en contexto lingüistico, los teóricos de Praga. Vindico el concepto de causación múltiple en mi trabajo de ámbito general, pero basado en una documentación hispácica: "Muttiple versus simple causation in linguistic change", en: To Honor Roman Jakobson: Essays on the occasion of his seventieth birthday, The Hague \& Paris, 1967, II, 1228-1246. 
terístico solo del español ${ }^{i 1}$, era otra vez imprescindible el concurso de varios factores: la actuación continua de la presión cultista; la ayuda eficaz que prestaba -lc-como nexo secundario (alçar, calçar, frente a solloçar ${ }^{72}$ ); la inconstancia que caracterizaba la evolución de -LS., -NS-, -RS- (y aun -rç-, ctc.), en posición media y final; y la predilección por ciertas normas silábico-acentuales, que impedía a los hablantes aceptar un adjetivo monosílabo como duz o doz (mientras dolc de ninguna manera era chocante en catalán, muy afín al francés en este respecto).

Así dulce, escudriñado bajo el prisma de un microscopio, ilustra como pocas voces españolas el engranaje de las fuerzas mecánicas, culturales y aun puramente estéticas - fuerzas que en parte parecen irresistibles y en parte dependen de la voluntad de los hablantes -cuyo conjunto determina el rumbo de un desarrollo lingüístico.

YaKov MALKIE:

Universidad de California, Berkeley.

71 Desde luego, conviene descontar el caso de rum. dulce, voz de carácter estrictamente popular; cf. lup 'lobo', urs 'oso', etc.

72 Sabido es que los verbos mellizos singult-īre y -ĀRE se convirtieron; por presiones léxicas, gramaticales y fonosimbólicas, en *subgluTtIĀRE; de ahí solloçar, que, a raíz de la metátesis, ya no presupone ningún nexo -LT-; tampoco lo exige sangloter en francés. 